\title{
PELATIHAN PEMBUATAN MEDIA PEMBELAJARAN UNTUK GURU KECAMATAN BUSUNGBIU
}

\author{
K. A. Hendra Pujawan ${ }^{1 *}$, M. P. Restami ${ }^{2}$ \\ ${ }^{1 *}$ Jurusan Manajemen Informatika, Politeknik Ganesha Guru \\ 2 Jurusan Teknik Komputer, Politeknik Ganesha Guru \\ ${ }^{*}$ Corresponding author : \\ E-mail: hendrapujawan@gmail.com
}

Diterima 30 April 2018, Disetujui 5 Mei 2018

\begin{abstract}
ABSTRAK
Pelatihan pengembangan media pembelajaran multimedia dengan pemanfaatan program Swishmax bertujuan untuk memberikan ketrampilan dalam pembuatan media pembelajaran multimedia yang menarik dengan cara yang relatif mudah. Dengan dikuasainya media pembelajaran multimedia oleh para guru SMP diharapkan akan pemicu minat siswa untuk lebih bersemangat dalam mengikuti pelajaran, dan pada akhirnya akan meningkatkan kualitas pembelajaran secara keseluruhan. Metode yang diterapkan dalam kegiatan ini adalah Metode Presentasi mengenai pengenalan software, kemanfaataannya, dan penerapannya dalam pembuatan media pembelajaran interaktif, Metode Demonstrasi mengenai pengoperasionalisasian program dan Metode Praktik yaitu pembuatan media pembelajaran secara langsung oleh peserta sesuai dengan mata pelajaran masing-masing dengan pemanfaatan program Swishmax. Metode evaluasi dengan mengamati perbedaan kemampuan guru sebelum dan setelah pelatihan. Dari hasil yang dicapai terlihat peningkatan kemampuan yang cukup signifikan dibanding dengan sebelum dilatih, sehingga dapat disimpulkan bahwa kegiatan ini berhasil meningkatkan kemampuan peserta. Evaluasi hasil dilihat dari penilaian tugas praktik yang menggambarkan keberhasilan materi yang telah disajikan. Selain itu juga dicermati kinerja dan partisipasi para peserta. Di akhir kegiatan Tim menjaring data kebermaknaan program pada para peserta. Diharapkan agar program pelatihan ini terus diadakan karena sangat dirasakan manfaatnya untuk meningkatkan kualitas pembelajaran.
\end{abstract}

Kata Kunci : Pelatihan Media Pembelajaran, Program Swishmax, Guru SMP

\begin{abstract}
Training development of multimedia learning media with Swishmax program utilization aims to provide skills in making multimedia learning media interesting in a relatively easy way. By mastering multimedia learning media by junior high school teachers, it is hoped that the students will be more motivated to participate in lessons, and will ultimately improve the quality of learning as a whole. The method applied in this activity is Presentation Method about the introduction of software, its usefulness, and its application in making of interactive learning media, Demonstration Method about operationalization of program and Practice Method that is making of instructional media directly by the participant in accordance with their respective subjects with utilization of Swishmaxprogram . Evaluation method by observing differences in teacher ability before and after training. From the results achieved seen a significant increase in ability compared with before being trained, so it can be concluded that this activity successfully improve the ability of participants. Evaluation of the results seen from the assessment of practical tasks that describe the success of material that has been presented. Also observed the performance and participation of the participants. At the end of the activity the Team captured the program's meaningful data to the participants. It is expected that this training program will continue to be held because it is very beneficial to improve the quality of learning.
\end{abstract}

Keywords: Training Media Learning, Swishmax Program, Junior High School Teachers

PENDAHULUAN
Media adalah sebuah alat yang $\begin{aligned} & \text { (Bovee, 1997). Media pembelajaran adalah } \\ & \text { mempunyai fungsi menyampaikan pesan }\end{aligned}$


menyampaikan pesan pembelajaran. Pembelajaran adalah sebuah proses komunikasi antara pembelajar, pengajar dan bahan ajar. Komunikasi tidak akan berjalan tanpa bantuan sarana penyampai pesan atau media.

Sampai saat ini media pembelajaran interaktif belum berkembang dengan optimal di Indonesia. Salah satu kendala pengembangan media pembelajaran interaktif adalah kurang dikuasainya teknologi pengembangan media interaktif oleh para pengajar, sehingga pengembangan materi pembelajaran interaktif dengan komputer kurang optimal.

Berdasarkan analisis situasi di atas maka tim pengabdi menyelelenggarakan kegiatan pelatihan pembuatan media pembelajaran bagi guru-guru SMP. dengan pemanfaatan program Swishmax. Swishmax adalah program aplikasi presentasi yang memiliki kemampuan membuat animasi yang kompleks dalam waktu cepat. Bagi yang sudah mengenal program Macromedia Flash, akan merasakan kemudahan dan kekuatan program ini.Apabila di dalam Macromedia Flash dibutuhkan waktu yang relative lama untuk membuat animasi yang kompleks, Swishmax memungkinkan untuk membuatnya dengan mudah tanpa kendala waktu (Syarif: 2005:1).

Hal lain yang menonjol dalam Swishmax adalah hasil karya dapat dieksport ke dalam format file SWF, yaitu format file yang digunakan oleh Macromedia Flash sehingga animasi yan dibuat dapat dimainkan di setiap PC yang sudah terinstalasi Flash Player. Animasi Flashmax dapat disisipkan ke dalam halaman Web, atau diimport ke dalam dokumen Microsoft Powerpoint.

Meskipun program aplikasi ini sebenarnya merupakan program untuk membuat presentasi namun fasilitas yang ada dapat dipergunakan untuk membuat program pembelajaran. Program yang dihasilkan pun akan cukup menarik. Keuntungan lainnya adalah bahwa program ini bisa disambungkan ke jaringan internet.

Pelatihan yang dikembangkan dan diterapkan ini diharapkan akan memberikan wawasan baru dalam pembuatan media pembelajaran, mengingat kemampuan program ini dalam hal pembuatan animasi untuk media pembelajaran multimedia yang menarik dengan caranya relatif mudah. Dengan dikuasainya media pembelajaran multimedia ini diharapkan akan pemicu minat siswa untuk lebih bersemangat dalam mengikuti pelajaran, dan pada akhirnya akan meningkatkan kualitas pembelajaran secara keseluruhan.
Ada tiga metode yang diterapkan dalam pelatihan ini, yaitu metode presentasi, metode demonstrasi, dan metode praktik. Metode presentasi diterapkan dalam pengenalan software, kemanfaataannya, dan penerapannya dalam pembuatan media pembelajaran interaktif, Metode Demonstrasi mengenai pengoperasionalisasian program dan Metode Praktik dimana guru-guru mempraktikkan secara langsung pembuatan media pembelajaran sesuai mata pelajaran masingmasing dengan pemanfaatan program Swishmax. Adapun langkah yang telah ditempuh dalam kegiatan PPM ini mencakup beberapa tahap berikut ini.

\section{Persiapan}

Tahap persiapan merupakan tahap awal sebelum pelaksanaan PPM. Dalam tahap ini ada beberapa hal yang dilakukan, yakni Koordinasi Internal, dilakukan oleh Tim untuk merencanakan pelaksanaan secara konseptual, operasional, serta job description masingmasing anggota, penentuan dan rekruitment peserta pelatihan. Dalam perekrutan peserta dipersyaratkan yang telah memiliki kemampuan yang memadai di bidang computer, pembuatan Instrumen PPM, seperti lembar presensi, angket, lembar kerja, persiapan konsumsi, publikasi, lokasi, dokumentasi, dan sebagainya.

\section{Pelaksanaan Pelatihan}

Tahap ini merupakan tahap pelatihan yang diberikan kepada para guru SMP yang merupakan utusan dari 15 SMP se Kabupaten Badung. Pelaksanaan pelatihan ini mencakup beberapa hal berikut.

\section{a. Penyajian Materi}

Materi yang disajikan terkait dengan pengenalan dan penggunaan program Swishmax untuk pembuatan media pembelajaran. Penyajian ini diploting dalam 6 hari tatap muka. Penyaji materi adalah tim pengabdi sendiri disesuaikan dengan bidang keahlian masing-masing. Materi yang tersajikan sebanyak 6 (enamt) bahasan yang masingmasing disajikan oleh anggota Tim Pengabdi sesuai bidang yang bersangkutan. Berikut tabel daftar materi dan pematerinya yang telah terlaksana dalam program PPM ini.

Pelaksanaan program ini melibatkan mahasiswa untuk membantu proses pembimbingan dan praktik agar kegiatan dapat berjalan lancar. Kegiatan tanya jawab dilakukan bersamaan dengan penyajian materi. Para peserta dapat langsung berdiskusi dengan para pemateri secara langsung untuk memahamkan materi dan sharing pengalaman terkait dengan masalah yang tengah dibahas dalam materi bersangkutan. 


\section{b. Penugasan Praktik}

Pada akhir materi peserta diberi tugas praktik sesuai materi yang telah disajikan untuk menggali penyerapan dan pemahaman materi serta melihat kreativitasnya dalam berkarya. Dalam pelatihan ini para guru ditugaskan untuk membuat satu media pembelajaran terkait mata kuliah yang diampu masing-masing guru. Tim pengabdi mendampingi, memandu dan mengarahkan serta memberikan solusi apabila timbul permasalahan selama penugasan praktik.

c. Evaluasi dan Penyempurnaan Karya Media Pembelajaran oleh Tim

Pada akhir pelatihan, media yang telah dibuat oleh para guru dikumpulkan dan dinilai oleh tim pengabdi kemudian disempurnakan oleh tim untuk kemudian dikembalikan kembali kepada peserta agar dapat digunakan untuk mengajar. Tindakan ini dilakukan mengingat karya media yang dihasilkan para guru masih perlu penyempurnaan, dan tim tim pengabdi ingin agar media pembelajaran betul-betul dapat segera dimanfaatkan untuk mengajar.

\section{d. Refleksi dan Penutupan Program PPM}

Di akhir kegiatan peserta dan Tim melakukan refleksi hasil pelatihan dan para peserta juga memberikan evaluasi akan pelatihan ini. Peserta mendapatkan koreksi dan evaluasi secara langsung terkait hasil karya mereka.

Setelah semua kegiatan yang telah direncanakan terlaksana, ketua tim PPM menutup program dan memberikan pesan kepada segenap peserta pelatihan untuk menerapkan apa yang telah didapatkan untuk memperbaiki media pembelajaran di sekolah masing-masing. Diharapkan pada PPM yang akan akan datang program ini dapat dilanjutkan lagi dan dapat lebih menjangkau jumlah sekolah lain tak hanya tingkat Sekolah Menengah Pertama (SMP) saja, sehingga kebermanfaatan program ini dapat dirasakan oleh sekolah yang lebih banyak.

\section{HASIL DAN PEMBAHASAN}

Guru merupakan salah satu unsur yang menggerakkan pendidikan di Indonesia. Namun, tanpa wawasan yang selalu dikembangkan dan di-up grade maka guru akan makin ketinggalan di era sekarang. Apalagi kebutuhan siswa juga makin berkembang. Lebih lagi, pemanfaatan teknologi di kalangan guru masih dianggap memprihatinkan. Kondisi ini dipengaruhi juga oleh kurangnya fasilitas penunjang pengembangan teknologi pembelajaran disamping sumber daya manusia yang menguasai teknologi masih kurang memadai. $\begin{array}{cccr} & \text { Pelatihan ini memberikan beberapa } \\ \text { materi } & \text { yang terkait dengan upaya }\end{array}$ mengembangkan media pembelajaran interaktif agar pembelajaran yang diberikan oleh guru menjadi lebih atraktif sehingga meningkatkan minat dan kualitas belajar siswa. Materi yang disajikan oleh pengabdi dapat diterima, dicerna, dan dipahami peserta dengan baik. Jumlah peserta yang sebanding dengan jumlah pengabdi yang berperan sebagai instruktur dan tutor menjadikan pelatihan ini menjadi lebih kondusif. Hal ini didukung pula dengan kemampuan peserta di bidang computer telah cukup memadai karena pada proses perekrutan telah ditetapkan standar minimal peserta harus telah menguasai computer dasar sehingga pelatihan dapat berjalan lancer dan para peserta dapat berkomunikasi dengan para pembicara dan peserta lain dengan lebih baik.

Berdasarkan diskusi yang dilaksanakan setelah pemapatran materi, dapat dilihat bahwa para guru dapat memahami urgensi pengembangan media pembelajaran, mampu mengenal fungsi program Swishmax, mampu membuat media pembelajaran interktif sesuai dengan bidang/mata pelajaran yang diampu oleh masing-masing guru. Selanjutnya berdasar hasil praktik juga dapat dilihat bahwa para guru mampu mengetahui manfaat program Swishmax untuk membuat media pembelajaran, mengenal tools Swishmax dan kegunaannya, Membuat objek shape, menyisipkan Objek Movie dan Sound, membuat Efek animasi, membuat Tombol dengan Swishscript, dan mampu membuat media pembelajaran interaktif dengan memanfaatkan program Swishmax.

Berdasarkan hasil karya media yang dibuat para guru, tim juga membuat lembar evaluasi dan menilai karya para guru dan didapat hasil rata-rata B (Baik), dan ada dua orang guru yang mendapat nilai SB (sangat baik).Evaluasi kegiatan dilakukan selama proses kegiatan berlangsung, yaitu pada saat peserta kegiatan melaksanakan proses pembuatan media pembelajaran dengan Swishmax . Evaluasi kegiatan PPM ini dilakukan dengan beberapa cara. Evaluasi hasil dilihat dari tugas praktik para peserta yang ada. Hasil praktiknya dinilai dan hal itu menggambarkan keberhasilan materi yang telah disajikan. Selain itu, secara proses juga dicermati kinerja dan kesertaan para peserta. Di akhir kegiatan Tim menjaring data kebermaknaan program pada para peserta.

Teknik evaluasi dilakukan dengan cara observasi, yaitu melihat bagaimana kualitas karya yang dihasilkan. Melakukan wawancara yaitu memberi berbagai pertanyaan yang terkait dengan pelaksanaan kegiatan baik secara 
individu maupun secara kelompok. Selain itu, memberi angket untuk mengetahui bagaimana tanggapan peserta tentang pelaksanaan kegiatan pelatihan pembuatan media pembelajaran interaktif dengan pemanfaatan program Swishmax yang telah dilaksanakan.

Untuk menjaring respon peserta terhadap kebermanfaatan dan kebermaknaan program ini dilakukan evaluasi respon terhadap kegiatan pelatihan. Berikut adalah tabel instrumen evaluasi respon peserta terhadap kegiatan pelatihan pembuatan media pembelajaran interaktif dengan pemanfaatan program Swishmax guru-guru SMP seKabupaten Badung.

Tabel 1. Lembar Evaluasi

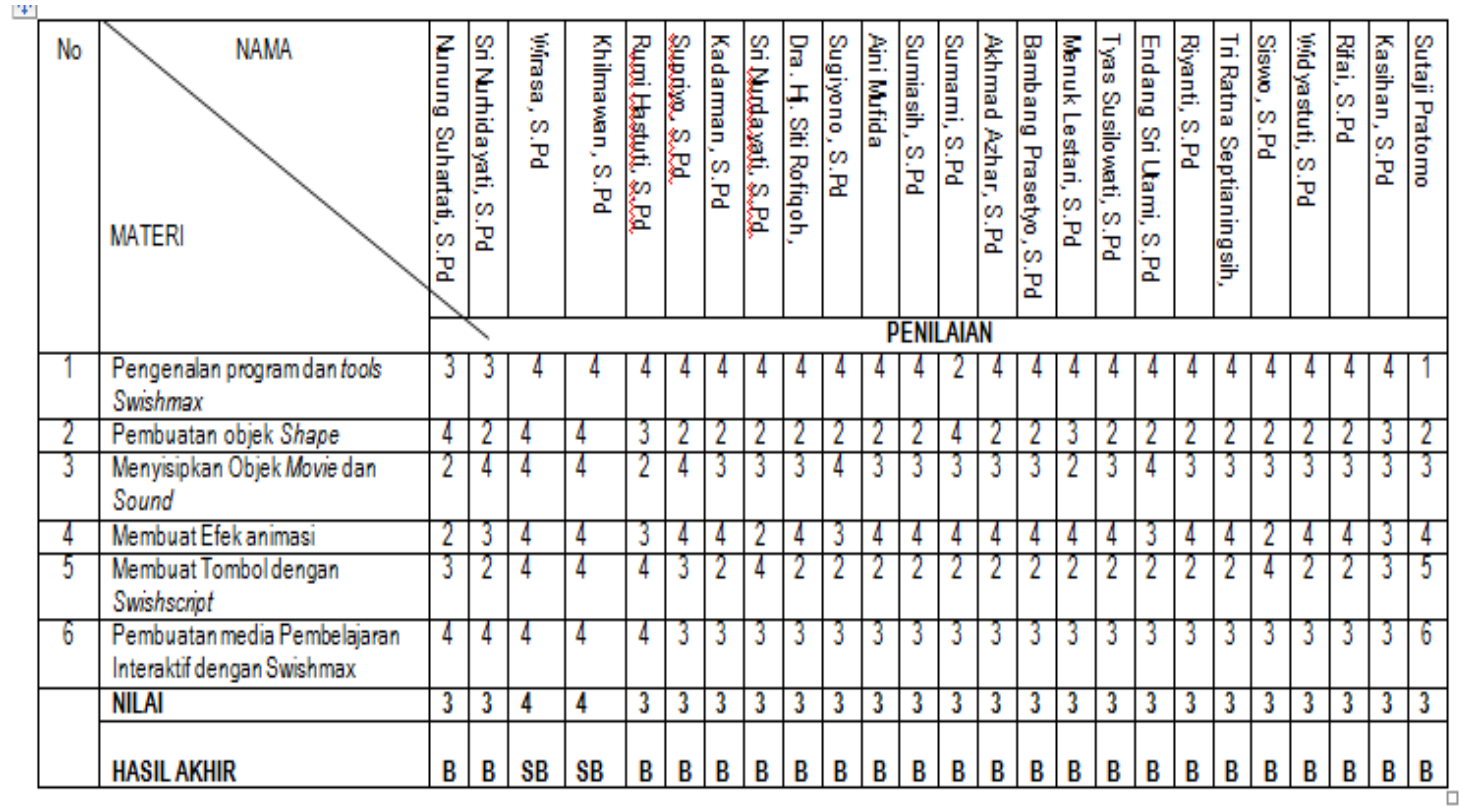

Skor:

1 :Kurang $(\mathrm{K})$

2 :Cukup (C)

3 : Baik (B)

4 :Sangat Baik (SB)

Tabel 2. Instrumen Evaluasi Respon Peserta terhadap Kegiatan Pelatihan

\begin{tabular}{|l|l|l|l|l|l|l|}
\hline No. & \multicolumn{1}{|c|}{ Pernyataan Peserta } & SB & B & S & KB & TB \\
\hline 1. & Kebermanfaatan kegiatan pelatihan & & & & & \\
\hline 2. & $\begin{array}{l}\text { Pelaksanaan kegiatan bagi } \\
\text { peningkatan kualitas media } \\
\text { pembelajaran }\end{array}$ & & & & & \\
\hline 3. & $\begin{array}{l}\text { Pengetahuan tentang operasionalisasi } \\
\text { program }\end{array}$ & & & & & \\
\hline 6. & $\begin{array}{l}\text { Pengetahuan tentang proses } \\
\text { pembuatan media pembelajaran } \\
\text { dengan pemanfaatan Program } \\
\text { Swishmax }\end{array}$ & & & & & \\
\hline 7. & $\begin{array}{l}\text { Hasil karya yang dihasilkan setelah } \\
\text { pelaksanaan pelatihan }\end{array}$ & & & & & \\
\hline
\end{tabular}

Keterangan:

SB : Sangat Baik

B : Baik

$S$ : Sedang

KB : Kurang Baik

TB : Tidak Baik 


\section{SIMPULAN DAN SARAN}

Simpulan

Berdasar hasil pelaksanaan kegiatan pengabdian kepada masyarakat ini dan uraian pembahasan di atas, dapat disimpulkan beberapa hal sebagai berikut ini.

1. Pelatihan ini memberikan beberapa materi yang terkait dengan upaya meningkatkan kualitas pembelajaran dengan pemberikan pengetahuan mengenai pemanfaatan Program Swishmax untuk membuat media pembelajaran interaktif yang atraktif dan interaktif.

2. Materi yang disajikan dapat diterima, dicerna, dan dipahami peserta dengan baik.

3. Kegiatan berlangsung lancar, tepat waktu dan sesuai dengan yang diharapkan

\section{Saran}

Adapun saran yang dapat diberikan terkait pengabdian ini adalah sebagai berikut:

1. Hendaknya program ini dapat terus berlanjut sehingga lebih banyak lagi sekolah yang dapat merasakan manfaatnya.

2. Para guru peserta pelatihan diharapkan dapat ikut aktif berperan dalam meningkatkan kualitas pembelajaran di sekolah masingmasing dan menularkan ilmu yang diperoleh kepada guru-guru lain di sekolah mereka.

\section{DAFTAR RUJUKAN}

Arry Maulana Syarif. 2005. Cara Cepat Membuat Animasi Flash menggunakan Swishmax. Yogyakarta: Penerbit Andi.

Anderson, Ronald A. 1994. Pemilihan dan Pengembangan Media untuk Pembelajaran, terjemahan oleh Yusufhadi Miarso, dkk. Jakarta: PT. Raja Grafindo Persada.

Miarso, Yusufhadi. 2004. Menyemai Benih Teknologi Pendidikan. Jakarta: Prenada Media.

Purnomo. 1996. Strategi Pengajaran. Yogyakarta: Universitas Sanata Dharma.

Juhaeri. 2009. Pengantar Multimedia Untuk Media Pembelajaran -bagian 2Published: July 10, 2009 . dari http://tutorial.babastudio.com/

Joyce, Bruce, Marsha, Weil, and Beverly Showers. (1992). Models of Teaching. Boston: Allyn and Bacon.

Mukminan. (1998). Belajar dan Pembelajaran. Yogyakarta: IKIP Yogyakarta.
Muhammad. (2004). Pedoman Pembelajaran Tuntas. Jakarta: Departemen Pendidikan Nasional. Direktorat Jenderal Pendidikan Dasar Menengah. Direktorat Pendidikan Lanjutan Pertama. 